\title{
Agôn
}

Revue des arts de la scène

Critiques | Saison 2013-2014

\section{Innocence d'Howard Barker, mise en scène d'Howard Barker et Gerrard McArthur}

Une alliance corrosive

Mathilde Bellin

\section{(2) OpenEdition \\ Journals}

Édition électronique

URL : http://journals.openedition.org/agon/2908

DOI : 10.4000/agon.2908

ISSN : 1961-8581

Éditeur

Association Agôn

Référence électronique

Mathilde Bellin, «Innocence d'Howard Barker, mise en scène d'Howard Barker et Gerrard McArthur », Agôn [En ligne], Critiques, mis en ligne le 01 mars 2014, consulté le 23 septembre 2020. URL : http:// journals.openedition.org/agon/2908; DOI : https://doi.org/10.4000/agon.2908

Ce document a été généré automatiquement le 23 septembre 2020.

Association Agôn et les auteurs des articles 


\title{
Innocence d'Howard Barker, mise en scène d'Howard Barker et Gerrard McArthur
}

Une alliance corrosive

\author{
Mathilde Bellin
}

\section{RÉFÉRENCE}

Innocence - d'Howard Barker, compagnie Nöjd

- du 21 janvier au 1er février, Théâtre des Célestins à Lyon

- en tournée : le 4 février, Théâtre Jean Vilar, Bourgoin-Jallieu ; le 7 février, Théâtre du Parc - Andrézieux-Bouthéon ; les 14 et 15 février, château Rouge, Annemasse ; le 21 février, Théâtre de Roanne ; le 26 février, Théâtre de Villefranche-sur-Saône - http://associationnojd.blogspot.fr/p/innocence.html

1 Le projet Innocence est né de la rencontre entre Aurélie Pitrat, membre fondateur de la compagnie Nöjd et Howard Barker, auteur, metteur en scène et théoricien britannique du théâtre de la catastrophe; théâtre qui expérimente la cruauté du monde et son étrange beauté. La pièce se situe au moment de la révolution française : la famille royale, emprisonnée et soumise au dénuement le plus extrême, attend son jugement, certaine de sa mort imminente. Innocence fait le récit de l'accusation d'inceste émise par le peuple contre la reine Caroline (figure de Marie-Antoinette) et son fils.

2 Howard Barker affirme avoir trouvé en la jeune compagnie lyonnaise des acteurs capables de relever le défi exigeant qu'impose son écriture. Il a vu juste. Luttant avec un texte puissant, truculent, riche, à l'énergie baroque, les acteurs de la compagnie Nöjd s'éloignent de tout jeu psychologisant pour entrer au plus profond de la chair même de la parole de Barker. Contrairement à beaucoup d'écritures contemporaines tentées par le silence, celle-ci est incisive, équivoque et son trouble opère. Le malaise se crée et les Nöjd, tout en conservant l'humour caractéristique de leur travail, donnent à 
cette tragédie une tonalité caustique bienvenue, qui souligne la force corrosive de ce texte si cinglant dans son immoralité. La rencontre entre cette jeune compagnie française aux airs impudents, forte de son répertoire habituellement comique et de son jeu désinvolte, et cette parole poétique foncièrement tragique donne lieu à un beau moment de théâtre, où c'est bel et bien l'acteur qui est au centre de la création : Aurélie Pitrat et ses acolytes déploient corps et voix avec une grande intensité et une impressionnante palette de nuances, de la douleur à l'extase, dans un espace dédié au langage.

Innocence

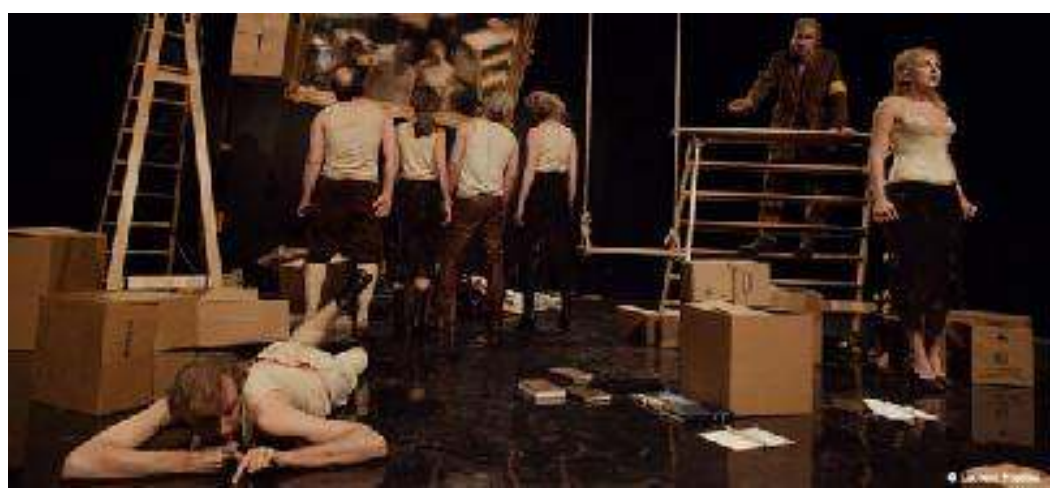

(c) Laurent Nicolas

Dirigés par Howard Barker en personne, les Nöjd, fiévreux et forcenés, affrontent avec brio la musicalité de cette langue, pour mieux en illustrer la dimension subversive : en effet, les événements historiques ne sont que prétextes à une spéculation morale. Innocence (en anglais The Gaoler's ache for the nearly dead) n'est pas comme on pourrait le croire une pièce historique mais un drame politique et moral aux accents très actuels. Et c'est cela que les Nöjd nous révèlent, avec ce qu'il faut d'effronterie, de fougue et d'aplomb pour ne pas faire sombrer le drame dans l'anecdotique. Innocence nous parle ainsi avec habilité et mordant de thèmes prégnants dans notre société contemporaine, tels que l'abolition du secret politique, la disparition de la sphère privées et le diktat de la transparence. La reine, Aurélie Pitrat, et son fils sont comme mis sur écoute, notamment grâce à cette figure du geôlier - interprété par Jean-Philippe Salério planant au-dessus de leur tête comme un oiseau de malheur, en costume noir, perché en haut d'un escabeau qui surplombe la scène pour mieux les observer. Une atmosphère d'oppression malsaine se crée peu à peu, non seulement grâce à la virtuosité et le style de jeu de la compagnie, mais aussi avec l'aide des créateurs sons et lumières : cris de foule, grincement de portes et éclairage tantôt obscur tantôt zébré de violents éclairs lumineux mettent à nu le corps des acteurs.

La compagnie n'ancre pas son spectacle dans une époque précise et ses choix scéniques habiles permettent de faire aisément l'analogie entre 1789 et notre époque contemporaine. La temporalité de la scène oscille entre souvenirs d'une époque révolue, grâce aux costumes d'inspiration classique des servantes, et projections des modes du renouveau du XXe siècle. Ce jeu subtil sur l'ambivalence des âges historiques déjoue tout réalisme, et ajoute au caractère exemplaire et archétypal de la détresse immorale des personnages. L'apport des choix scéniques amplifie cette dimension de drame politique où l'on devient soi-même voyeur. L'espace, étriqué et transformé en un huis-clos que délimite un amas de vieux cartons qui jonchent le sol de la cellule, tels des 
détritus parmi lesquels on abandonne la reine et son fils, accueille savamment les acteurs, plus acerbes et cinglants que jamais.

5 À contre-courant de la tyrannie de la société de la transparence, qui sous couvert d'exigences démocratiques abolit toute sphère privée, Howard Barker déploie par une écriture mystérieuse et forte un théâtre du secret. S'emparant de celle-ci, les Nöjd exposent les dessous confidentiels de cette tragédie à la lumière du jour, et nous bouleversent à mesure que leur désinvolture se fait plus véhémente et plus grave. 